\title{
Effect of Long-Term Diabetes on Serotonin-Mediated Contraction in Carotid Arteries from Streptozotocin-Induced Diabetic Male and Female Rats
}

\author{
Shun Watanabe, ${ }^{\#}$ Takayuki Matsumoto, ${ }^{\#}$ Makoto Ando, Shota Kobayashi, Maika Iguchi, \\ Kumiko Taguchi, and Tsuneo Kobayashi* \\ Department of Physiology and Morphology, Institute of Medicinal Chemistry, Hoshi University; Shinagawa-ku, Tokyo \\ 142-8501, Japan.
}

Received April 3, 2016; accepted July 26, 2016

\begin{abstract}
An accumulating body of evidence suggests that males and females differ in vascular function in arteries under pathophysiological states. In this study, we tested whether there was a sex difference associated with serotonin (5-hydroxytryptamine, 5-HT)-mediated contraction in the carotid arteries of long-term streptozotocin (STZ)-induced diabetic rats [viz. 23 or 24 weeks after STZ $(65 \mathrm{mg} / \mathrm{kg}$, intravenously (i.v.)) injection starting at 8 weeks old of rats]. In the control group, the 5-HT- and high-K ${ }^{+}$-induced contractions were greater in females than in males. In both sexes, treatment with STZ led to a decrease of 5-HT-induced contraction in carotid arteries compared to controls. In STZ-induced diabetic rats, the carotid arterial 5-HTinduced contraction was greater in female rats than in diabetic male rats. The high- $\mathrm{K}^{+}$-induced contraction was greater in diabetic female rats than in either age-matched female controls or diabetic male rats. Expression of the 5- $\mathrm{HT}_{2 \mathrm{~A}}$ receptor, which is the main receptor for 5-HT-induced contraction in rat carotid arteries, was similar among the four groups. These results suggest that decreased 5-HT-induced carotid arterial contraction is seen in both sexes under long-term STZ-induced diabetic conditions. Further, this reduction seems to be weaker in females than in males. This alteration of 5-HT-induced contraction may be partly associated with increased voltage-dependent $\mathrm{Ca}^{2+}$ channel activity.
\end{abstract}

Key words carotid artery; contraction; serotonin; sex difference; streptozotocin

Although women generally develop cardiovascular diseases several years later than men, this benefit may be diminished in diabetic individuals. The results of numerous epidemiological studies investigating the relationship between sex and the development of cardiovascular disease in diabetics have been inconsistent. ${ }^{1,2)}$ Alterations in the responsiveness of blood vessels to various hormones and/or neurotransmitters in patients of both sexes with diabetes mellitus are well established. ${ }^{3-6)}$ However, there is confounding evidence of vascular function between diabetics of both male and females.

The neurotransmitter serotonin [5-hydroxytriptamine (5-HT)] is an important factor that is involved in the regulation of several vascular functions, including blood flow, blood pressure, and vascular tone, in pathophysiological states. ${ }^{7-9)}$ Several reports by our research team ${ }^{10-12}$ and others ${ }^{3,13-15)}$ have found that alterations in vasocontraction induced by 5-HT were observed in patients with cardiovascular diseases as well as in those with diabetes. An accumulating body of evidence suggests that 5-HT plays a role in the development of diabetic complications. For example, sarpogrelate, an antagonist of the $5-\mathrm{HT}_{2 \mathrm{~A}}$ receptor, has beneficial effects against diabetic nephropathy, neuropathy, and diabetes-associated vascular dysfunction, including arterial stiffness and arteriosclerosis, in diabetic patients and animal models. ${ }^{16-19)}$ This relevant evidence suggests that the manipulation of 5-HT function can represent a critical therapeutic target in the case of diabetic vasculopathies. In the carotid artery, which supplies blood to the brain, we found increased 5-HT-induced contractions in type 2 diabetic Goto-Kakizaki rats. ${ }^{11)}$ More-

\footnotetext{
\# These authors contributed equally to this work.

* To whom correspondence should be addressed. e-mail: tkoba@hoshi.ac.jp
}

over, we very recently demonstrated that exposure to high insulin levels, but not high glucose levels, can increase 5-HTinduced contraction in rat carotid arteries. ${ }^{20)}$ However, at present, whether there are sex-associated differences in carotid arterial contraction induced by 5 -HT in chronic-stage diabetes remains unclear.

Type 1 diabetes can be induced by the injection of streptozotocin (STZ), which causes $\beta$-cell death in the pancreas and is commonly used to induce type 1 diabetes in experimental models. ${ }^{21)}$ The aims of our study were to investigate whether 5-HT-induced carotid arterial contraction would differ between males and females with STZ-induced diabetes.

\section{MATERIALS AND METHODS}

Animals Male and female Wistar rats (8 weeks old) were randomly divided into diabetic and non-diabetic (control) groups. Experimental type 1 diabetic rats were induced with a single intravenous injection of STZ $(65 \mathrm{mg} / \mathrm{kg}$ dissolved in citrate buffer), as described previously. ${ }^{22-24)}$ As a control, age-matched rats were injected with citrate buffer alone. All animals were given a standard laboratory diet and water $\mathrm{ad}$ libitum until the rats were 31 or 32 weeks old (viz. 23 or 24 weeks after STZ/buffer injection). This study was approved by the Hoshi University Animal Care and Use Committee, and all experiments were performed in accordance with "Guide for the Care and Use of Laboratory Animals" published by the U.S. National Institutes of Health and "Guide for the Care and Use of Laboratory Animals" adopted by the Committee on the Care and Use of Laboratory Animals of Hoshi University.

Measurement of Blood Parameters and Blood Pressure 
Plasma (nonfasting; taken at sacrifice) parameters and blood pressure (measured at 1 week before sacrifice) were measured as reported previously. ${ }^{25-27)}$ Blood glucose was measured by a glucose meter (OneTouch Ultra, LifeScan, Johnson \& Johnson Company, Milpitas, CA, U.S.A.). Plasma lipid parameters and plasma insulin were measured using commercially available kits (Wako Pure Chemical Industries, Ltd., Osaka, Japan and Shibayagi, Gunma, Japan, respectively). Systolic blood pressure was measured by the tail-cuff technique (model BP-98A; Softron, Tokyo, Japan).

Functional Study Vascular isometric force of the common carotid artery was recorded as described previously. ${ }^{20,28,29)}$ To generate concentration-response curves in modified Krebs-Henseleit solution [(in mм) $118.0 \mathrm{NaCl}, 4.7 \mathrm{KCl}$, 25.0 $\mathrm{NaHCO}_{3}, 1.8 \mathrm{CaCl}_{2}, 1.2 \mathrm{NaH}_{2} \mathrm{PO}_{4}, 1.2 \mathrm{MgSO}_{4}$, and 11.0 glucose] and 5-HT (serotonin hydrochloride, Sigma-Aldrich, St. Louis, MO, U.S.A) $\left(10^{-9}-3 \times 10^{-5} \mathrm{M}\right)$ or high-K $\mathrm{K}^{+}(10-80 \mathrm{~mm})$ was added cumulatively to the bath until a maximal response was achieved. To assess concentration-response curves for high- $\mathrm{K}^{+}(10-80 \mathrm{~mm})$, we removed an appropriate volume of solution from the bath and then added equal volumes of high $\left[\mathrm{K}^{+}\right]$solution as reported previously. ${ }^{11,30)}$

Immunoblotting Western blotting and data analysis were performed as previously described. ${ }^{11,20,26)}$ Primary antibodies were used as follows: $5-\mathrm{HT}_{2 \mathrm{~A}}$ receptor $(1: 500$, ImmunoStar, Hudson, WI, U.S.A) and $\beta$-actin (1:5000, Sigma-Aldrich).

Data and Statistical Analysis Data were expressed as the mean \pm standard error (S.E.). Concentration-response curves were analyzed using a nonlinear regression curvefitting program (Graph Pad Prism software ver. 5.0 for Mac, San Diego, CA, U.S.A.). Statistical analysis was performed using a one-way ANOVA followed by a Bonferroni's test for multiple comparisons. Statistical analysis of concentration-response curves were performed using a two-way ANOVA with repeated measures followed by a Bonferroni post-hoc test. ${ }^{*} p$ Values $<0.05$ were considered significant.

\section{RESULTS}

General Parameters As shown in Table 1, treatment with STZ (vs. control group) led to significant increases in left ventricle/body weight (BW) ratios, as well as glucose levels; however, significant decreases in BW and heart rate were observed in both the male and female groups. In male rats, STZ led to a significant increase blood pressure and a decrease in insulin levels and tended to increase total cholesterol and triglyceride levels. In female rats, STZ led to a significant increase in total cholesterol and triglyceride levels and tended to increase blood pressure. Surprisingly, the insulin levels were similar between the control and STZ groups in female rats.

5-HT and High-K ${ }^{+}$-Mediated Contractions The ring weight of the carotid artery was different between male and female rats with and without diabetes, whereas diabetes did not differentially affect the weight in either sex (Table 1). As shown in Fig. 1, diabetes led to decrease 5-HT-induced contraction in both sexes; whereas, high- $\mathrm{K}^{+}$-induced contraction did not change in males but increased in female rats (viz. control vs. diabetics). When we focused on sexes, both contractions induced by $5-\mathrm{HT}$ and high- $\mathrm{K}^{+}$increased in females (vs. males) with and without diabetes.

Expression of 5-HT ${ }_{2 \mathrm{~A}}$ Receptors in Carotid Arteries To investigate the possible mechanisms underlying the sex-associated differences associated with 5-HT-mediated contraction in STZ-induced rats, we examined protein expression of the $5-\mathrm{HT}_{2 \mathrm{~A}}$ receptor. ${ }^{7)}$ Unexpectedly, the expression was similar among the four groups (Fig. 2).

\section{DISCUSSION}

There is confounding evidence in the literature concerning the alteration of 5-HT-induced contraction in the arterial vessels of diabetes. In this study, long-term diabetes induced by STZ led to a reduction of 5-HT-induced contraction in rat carotid arteries in both male and female rats. Notably, the extent of the reduction of 5-HT-induced contraction was lower in females than in males: the contractile response to 5-HT was greater in the female diabetic group than in the male diabetic group. Nuno and Lamping ${ }^{3)}$ found that 5-HT-induced contraction was greater in mouse aortas of nondiabetic males than in those of females and that following diabetes development, 5-HT-induced contraction increased in males but not in females. Their study used diabetic mice for functional analysis at 12-16 weeks after the first measurement of hyperglycemia and injected STZ (2-3 injections at $100-150 \mathrm{mg} / \mathrm{kg}$, intraperitoneally (i.p.)). Sheykhzade et $a l^{31)}$ found that 5-HTinduced contraction in coronary arteries was similar between age-matched female control rats and long-term (34 weeks) STZ $(65 \mathrm{mg} / \mathrm{kg}$, intravenously (i.v.) at 10 weeks old)-induced

Table 1. Values of Various Parameters in STZ-Induced Diabetic and Control Male and Female Rats

\begin{tabular}{|c|c|c|c|c|}
\hline & \multicolumn{2}{|c|}{ Male } & \multicolumn{2}{|c|}{ Female } \\
\hline & Control & Diabetic & Control & Diabetic \\
\hline Body weight (g) & $613.2 \pm 9.4(10)$ & $368.6 \pm 14.2(8)^{*}$ & $332.7 \pm 6.1(9)^{*}$ & $245.5 \pm 9.3(9)^{\# \dagger}$ \\
\hline LV/BW (mg/g) & $1.62 \pm 0.03(10)$ & $2.50 \pm 0.07(8)^{*}$ & $1.94 \pm 0.05(9)^{*}$ & $2.54 \pm 0.11(9)^{\#}$ \\
\hline $\mathrm{SBP}(\mathrm{mmHg})$ & $105 \pm 4(10)$ & $136 \pm 6(8)^{*}$ & $103 \pm 3(9)$ & $120 \pm 4(9)$ \\
\hline HR (beats/min) & $332.1 \pm 10.2(10)$ & $254.3 \pm 9.4(8)^{*}$ & $354.4 \pm 16.5(9)$ & $253.9 \pm 9.3(9)^{\#}$ \\
\hline Glucose (mg/dL) & $111.8 \pm 3.3(10)$ & $550.8 \pm 15.6(8) *$ & $119.0 \pm 4.5(9)$ & $581.0 \pm 10.9(9)^{\#}$ \\
\hline Insulin $(\mathrm{ng} / \mathrm{mL})$ & $1.82 \pm 0.3(8)$ & $0.79 \pm 0.08(8)^{*}$ & $1.51 \pm 0.08(7)$ & $1.36 \pm 0.10$ \\
\hline T-Chol (mg/dL) & $115.8 \pm 6.5(10)$ & $145.6 \pm 6.9$ & $70.4 \pm 6.7(9)^{*}$ & $137.1 \pm 13.2(9)^{\#}$ \\
\hline TG (mg/dL) & $205.6 \pm 23.1(10)$ & $417.8 \pm 47.6(7)$ & $215.0 \pm 21.1$ & $461.4 \pm 90.7(9)^{\#}$ \\
\hline Ring weight (mg) & $0.93 \pm 0.05$ & $0.85 \pm 0.07$ & $0.62 \pm 0.04(9)^{*}$ & $0.51 \pm 0.04(9)^{\dagger}$ \\
\hline
\end{tabular}

Values are the mean \pm S.E. Number of experiments is shown within parentheses. LV; left ventricule, BW; body weight, SBP; systolic blood pressure, HR; heart rate, T-Chol; total cholesterol, TG; triglyceride. ${ }^{*} p<0.05 v s$. male control, ${ }^{\sharp} p<0.05 v$ s. female control, ${ }^{\dagger} p<0.05 v s$. male diabetic. 
A
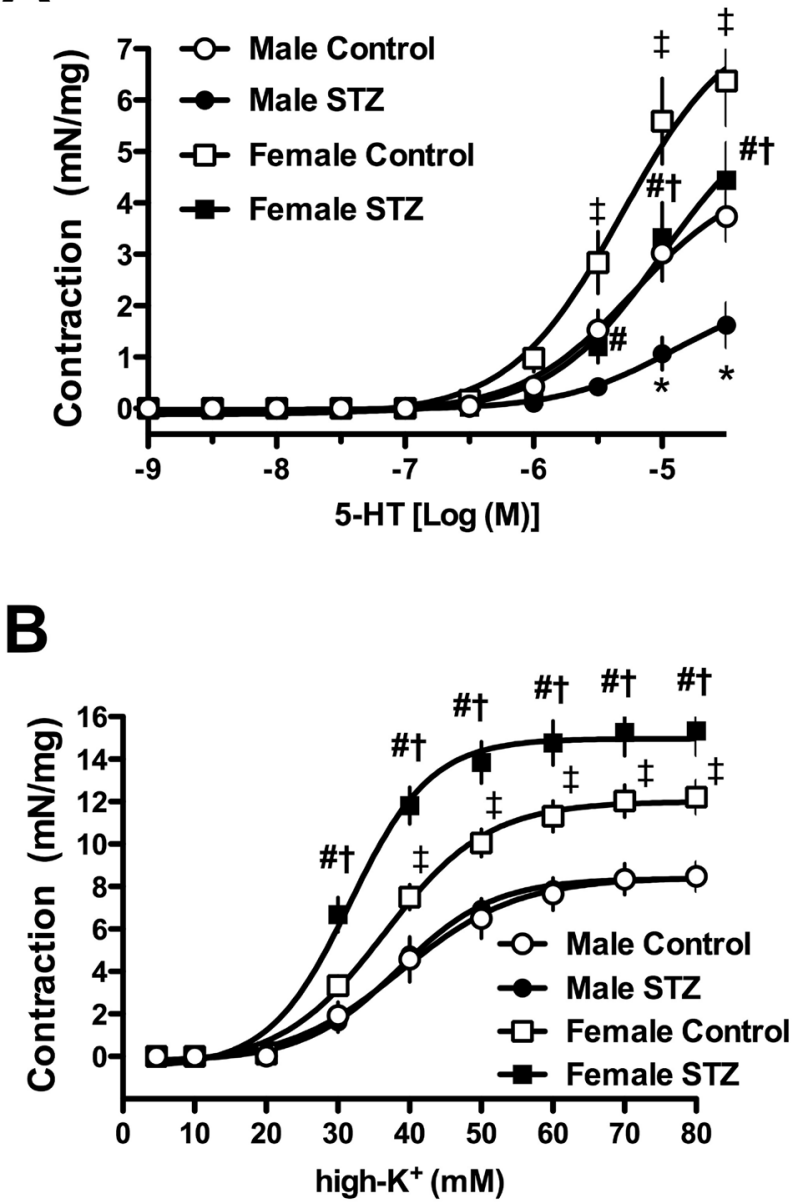

Fig. 1. Concentration-Response Curves for (A) 5-HT- and (B) High$\mathrm{K}^{+}$-Induced Contractions of Carotid Artery Rings Isolated from STZInduced Diabetic Male and Female Rats

The $y$-axis shows the increase in tension $(\mathrm{mN} / \mathrm{mg})$ measured at the peak response. Data are expressed as the mean \pm S.E. $n=8$ or 9 . $* p<0.05$, male control vs. male STZ. ${ }^{\sharp} p<0.05$, female control $v s$. female STZ. ${ }^{\dagger} p<0.05$, male STZ $v s$. female STZ. ${ }^{\star} p<0.05$, male control vs. female control.

diabetic female Wistar rats. Van Buren et al. ${ }^{32)}$ observed that in mesenteric resistance arteries in short-term (4 weeks) and long-term (40 weeks) STZ (40 mg/kg, i.v.)-induced diabetic rats, the 5-HT-induced contraction was similar to age-matched control rats; however, the 5-HT-induced contraction increased and decreased in the basilar artery in short-term and longterm STZ-induced diabetic rats, respectively. These discrepancies may result from vessel types, sex, or duration of disease.

The STZ-induced diabetic method is commonly used to generate type 1 diabetic animal models. ${ }^{21,33)}$ In this study, male rats treated with a single dose of STZ exhibited lower BW, hyperglycemia, and hypoinsulinemia than controls. However, in female rats (vs. controls), hypoinsulinemia was not seen in STZ-injected rats despite the expression of hyperglycemia and lower BW. These paradoxical data may be a result of $\beta$-cell recovery in female rats over time. Indeed, several reports suggested that STZ-injected female rats showed signs of partial spontaneous regeneration with increased circulating and pancreatic insulin levels within 1 year of the disease duration. ${ }^{34,35)}$ Such partial recovery from STZ-induced diabetes has been also found in adult rats treated with low concentration of STZ. ${ }^{36)}$ The lower susceptibility to the diabetogenic effects
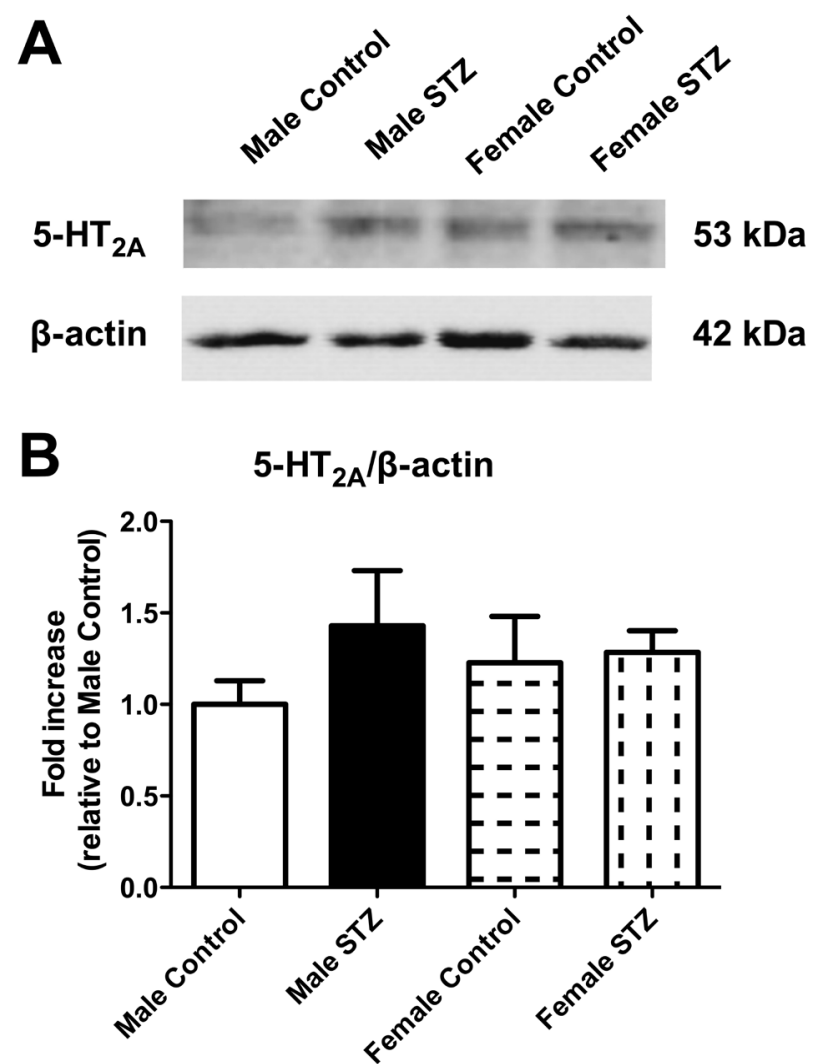

Fig. 2. Protein Expression of 5-HT $2 \mathrm{~A}$ Receptors in Carotid Arteries

(A) Representative Western blot is presented. (B) Corresponding densitometric analysis showing the expression of the $5-\mathrm{HT}_{2 \mathrm{~A}}$ receptor and $\beta$-actin. Results are presented as the fold increase relative to male control. Data are expressed as the mean \pm S.E. $n=5$ or 6 .

of STZ has been observed in female ${ }^{37)}$ and castrated male mice. $^{38)}$ These findings suggest that STZ sensitivity and/or status of $\beta$ cells may be different between males and females; however, further investigations on these findings are required. In the present study, we also found increased levels of blood lipid parameters (namely, total cholesterol and triglyceride) in the diabetic group compared with those in the control group in each sex, and the alteration of reactivity to 5-HT was seen in hyperlipidemic conditions. ${ }^{39,40)}$ Because the above blood parameters did not differ between male and female diabetic rats, these factors may not be associated with 5-HT-induced contraction in carotid arteries. Moreover, we very recently found that high insulin exposure, but not high glucose levels, led to enhanced 5-HT-induced contraction in rat carotid arteries. ${ }^{20}$ ) Therefore, we suggest that the insulin level is a determinant factor in contractile response to 5-HT in carotid arteries. Further investigation is required to identify causative factors in the alteration of 5-HT-induced vasocontraction between sexes.

Vascular contractile mechanisms are mainly divided into two mechanisms: calcium signals and changes in the contractile apparatus' sensitivity to calcium. ${ }^{41,42)}$ Indeed, these two signaling pathways are utilized in $5-\mathrm{HT}_{2 \mathrm{~A}}$ receptor-mediated responses in vascular smooth muscle. ${ }^{9,11-14,20,43)}$ In the present study, high- $\mathrm{K}^{+}$-induced contraction in diabetic female rats was greater than in control female rats and diabetic male rats. We suggest that the greater response to 5-HT in diabetic female carotid arteries relative to that of diabetic males may be partly attributable to increased voltage-gated calcium channel activity rather than $5-\mathrm{HT}_{2 \mathrm{~A}}$ receptor expression. Because insulin 
can modulate intracellular calcium levels, ${ }^{44,45)}$ the different insulin levels under diabetic conditions between sexes may be also contributed to altered high- $\mathrm{K}^{+}$-induced contraction. However, further investigation is required to establish the mechanisms underlying these factors.

In conclusion, we suggest that decreased 5-HT-induced carotid arterial contraction is observed in both sexes under longterm STZ-induced diabetes and the extent of the reduction differs between sexes. Our findings provide evidence of sex differences related to reactivity to 5-HT in long-term diabetic states and may contribute to the development of new strategies for the treatment of diabetes-associated vascular dysfunction.

Acknowledgments We thank H. Sashikubi, A. Suwa, M. Takeuchi, M. Takahashi, M. Nagata, S. Hotozuka, J. Nomoto, and M. Majima for technical assistance. This study was supported in part by JSPS KAKENHI Grants 26460107 (to T.M.), 15K21419 (to K.T.), and 15K07975 (to T.K.).

Conflict of Interest The authors declare no conflict of interest.

\section{REFERENCES}

1) Kajiwara A, Miyagawa H, Saruwatari J, Kita A, Sakata M, Kawata Y, Oniki K, Yoshida A, Jinnouchi H, Nakagawa K. Gender differences in the incidence and progression of diabetic retinopathy among Japanese patients with type 2 diabetes mellitus: a clinicbased retrospective longitudianal study. Diabetes Res. Clin. Pract., 103, e7-e10 (2014).

2) Franconi F, Campesi I, Occhioni S, Tonolo G. Sex-gender differences in diabetes vascular complications and treatment. Endocr. Metab. Immune Disord. Drug Targets, 12, 179-196 (2012).

3) Nuno DW, Lamping KG. The role of rho kinase in sex-dependent vascular dysfunction in type 1 diabetes. Exp. Diabetes Res., 2010, 176361 (2010).

4) Matsumoto T, Kakami M, Kobayashi T, Kamata K. Gender differences in vascular reactivity to endothelin-1 (1-31) in mesenteric arteries from diabetic mice. Peptides, 29, 1338-1346 (2008).

5) Taguchi K, Morishige A, Matsumoto T, Kamata K, Kobayashi T. Enhanced estradiol-induced vasorelaxation in aortas from type 2 diabetic mice may reflect a compensatory role of p38 MAPK-mediated eNOS activation. Pflugers Arch., 464, 205-215 (2012b).

6) Takenouchi Y, Kobayashi T, Taguchi K, Matsumoto T, Kamata K. Gender differences in vascular reactivity of aortas from streptozotocin-induced diabetic mice. Biol. Pharm. Bull., 33, 1692-1697 (2010).

7) Watts SW, Morrison SF, Davis RP, Barman SM. Serotonin and blood pressure regulation. Pharmacol. Rev., 64, 359-388 (2012).

8) Machida T, Iizuka K, Hirafuji M. 5-Hydroxytryptamine and its receptors in systemic vascular walls. Biol. Pharm. Bull., 36, 14161419 (2013)

9) Gamoh S, Hisa H, Yamamoto R. 5-Hydroxytryptamine receptors as targets for drug therapies of vascular-related diseases. Biol. Pharm. Bull., 36, 1410-1415 (2013).

10) Matsumoto $T$, Kobayashi $T$, Ishida K, Taguchi K, Kamata K. Enhancement of mesenteric artery contraction to 5-HT depends on Rho kinase and Src kinase pathways in the ob/ob mouse model of type 2 diabetes. Br. J. Pharmacol., 160, 1092-1104 (2010).

11) Matsumoto $\mathrm{T}$, Watanabe $\mathrm{S}$, Taguchi K, Kobayashi T. Mechanisms underlying increased serotonin-induced contraction in carotid arteries from chronic type 2 diabetic Goto-Kakizaki rats. Pharmacol. Res., 87, 123-132 (2014).

12) Watanabe S, Matsumoto $T$, Ando M, Adachi $T$, Kobayashi S, Iguchi M, Takeuchi M, Taguchi K, Kobayashi T. Multiple activation mechanisms of serotonin-mediated contraction in the carotid arteries obtained from spontaneously hypertensive rats. Pflugers Arch., 468, 1271-1282 (2016).

13) Nelson PM, Harrod JS, Lamping KG. 5HT(2A) and 5HT(2B) receptors contribute to serotonin-induced vascular dysfunction in diabetes. Exp. Diabetes Res., 2012, 398406 (2012).

14) Nuno DW, Harrod JS, Lamping KG. Sex-dependent differences in Rho activation contribute to contractile dysfunction in type 2 diabetic mice. Am. J. Physiol. Heart Circ. Physiol., 297, H1469-H1477 (2009).

15) Miranda FJ, Alabadi JA, Llorens S, Ruiz de Apodaca RF, Centeno JM, Alborch E. Experimental diabetes induces hyperreactivity of rabbit renal artery to 5-hydroxytryptamine. Eur. J. Pharmacol., 439, 121-127 (2002).

16) Takahashi T, Yano M, Minami J, Haraguchi T, Koga N, Higashi K, Kobori S. Sarpogrelate hydrochloride, a serotonin2A receptor antagonist, reduces albuminuria in diabetic patients with earlystage diabetic nephropathy. Diabetes Res. Clin. Pract., 58, 123-129 (2002).

17) Cameron NE, Cotter MA. The effects of 5-hydroxytryptamine 5-HT2 receptor antagonists on nerve conduction velocity and endoneurial perfusion in diabetic rats. Naunyn Schmiedebergs Arch. Pharmacol., 367, 607-614 (2003).

18) Yamakawa J, Takahashi T, Saegusa S, Moriya J, Itoh T, Kusaka K, Kawaura K, Wang XQ, Kanda T. Effect of the serotonin blocker sarpogrelate on circulating interleukin-18 levels in patients with diabetes and arteriosclerosis obliterans. J. Int. Med. Res., 32, 166-169 (2004).

19) Nagayama D, Ohira M, Saiki A, Shirai K, Tatsuno I. Sarpogrelate hydrochloride decreases cardio-ankle vascular index accompanied by increased serum lipoprotein lipase mass in type 2 diabetic patients. Int. Heart J., 55, 337-341 (2014).

20) Watanabe S, Matsumoto T, Oda M, Yamada K, Takagi J, Taguchi $\mathrm{K}$, Kobayashi $\mathrm{T}$. Insulin augments serotonin-induced contraction via activation of the IR/PI3K/PDK1 pathway in the rat carotid artery. Pflugers Arch., 468, 667-677 (2016).

21) King AJ. The use of animal models in diabetes research. Br. J. Pharmacol., 166, 877-894 (2012).

22) Kobayashi $T$, Nogami $T$, Taguchi $K$, Matsumoto $T$, Kamata K. Diabetic state, high plasma insulin and angiotensin II combine to augment endothelin-1-induced vasoconstriction via ETA and ERK. Br. J. Pharmacol., 155, 974-983 (2008).

23) Matsumoto T, Kobayashi T, Kamata K. Alterations in EDHF-type relaxation and phosphodiesterase activity in mesenteric arteries from diabetic rats. Am. J. Physiol. Heart Circ. Physiol., 285, H283H291 (2003).

24) Matsumoto $T$, Noguchi E, Kobayashi T, Kamata K. Mechanisms underlying the chronic pioglitazone treatment-induced improvement in the impaired endothelium-dependent relaxation seen in aortas from diabetic rats. Free Radic. Biol. Med., 42, 993-1007 (2007).

25) Matsumoto $T$, Nakayama N, Ishida K, Kobayashi T, Kamata K. Eicosapentaenoic acid improves imbalance between vasodilator and vasoconstrictor actions of endothelium-derived factors in mesenteric arteries from rats at chronic stage of type 2 diabetes. J. Pharmacol. Exp. Ther., 329, 324-334 (2009).

26) Matsumoto $T$, Watanabe $S$, Ando M, Yamada K, Iguchi M, Taguchi $\mathrm{K}$, Kobayashi T. Diabetes and age-related differences in vascular functions or renal artery: Possible involvement of endoplasmic reticulum stress. Rejuvenation Res., 19, 41-52 (2016).

27) Taguchi K, Hida M, Matsumoto T, Ikeuchi-Takahashi Y, Onishi H, Kobayashi T. Effect of short-term polyphenol treatment on endothelial dysfunction and thromboxane A2 levels in streptozotocininduced diabetic mice. Biol. Pharm. Bull., 37, 1056-1061 (2014).

28) Matsumoto T, Watanabe S, Kawamura R, Taguchi K, Kobayashi T. Epigallocatechin gallate attenuates ET-1-induced contraction in carotid artery from type 2 diabetic OLETF rat at chronic stage of 
diabetes. Life Sci., 118, 200-205 (2014).

29) Matsumoto T, Watanabe S, Yamada K, Ando M, Iguchi M, Taguchi $\mathrm{K}$, Kobayashi T. Relaxation induced by atrial natriuretic peptide is impaired in carotid but not renal arteries from spontaneously hypertensive rats due to reduced BKCa channel activity. Biol. Pharm. Bull., 38, 1801-1808 (2015).

30) Kobayashi T, Kaneda A, Kamata K. Possible involvement of IGF-1 receptor and IGF-binding protein in insulin-induced enhancement of noradrenaline response in diabetic rat aorta. Br. J. Pharmacol., 140, 285-294 (2003).

31) Sheykhzade M, Dalsgaard GT, Johansen T, Nyborg NC. The effect of long-term streptozotocin-induced diabetes on contractile and relaxation responses of coronary arteries: selective attenuation of CGRP-induced relaxations. Br. J. Pharmacol., 129, 1212-1218 (2000).

32) Van Buren T, Vleeming W, Krutzen MM, Van de Kuil T, Gispen WH, De Wildt DJ. Vascular responses of isolated mesenteric resistance and basilar arteries from short- and long-term diabetic rats. Naunyn Schmiedebergs Arch. Pharmacol., 358, 663-670 (1998).

33) Chatzigeorgiou A, Halaps A, Kalafatakis K, Kamper E. The use of animal models in the study of diabetes mellitus. In Vivo, 23, 245-258 (2009).

34) Šviglerová J, Mudra J, Tonar Z, Slavîková J, Kuncová J. Alteration of the cardiac sympathetic innervation is modulated by duration of diabetes in female rats. Exp. Diabetes Res., 2011, 835932 (2011).

35) Kuncová J, Sviglerova J, Tonar Z, Slavikova J. Heterogenous changes in neuropeptide $\mathrm{Y}$, norepinephrine and epinephrine concentrations in the hearts of diabetic rats. Auton. Neurosci., 121, 7-15 (2005).

36) $\overline{\mathrm{Su} \text { EN }}$, Alder VA, Yu DY, Cringle SJ, Yogesan K. Continued progression of retinopathy despite spontaneous recovery to normoglycemia in a long-term study of streptozotocin-induced diabetes in rats. Graefes Arch. Clin. Exp. Ophthalmol., 238, 163-173 (2000).

37) Rossini AA, Williams RM, Appel MC, Like AA. Sex differences in the multiple-dose streptozotocin model of diabetes. Endocrinology,
103, 1518-1520 (1978).

38) Leiter EH. Multiple low-dose streptozotocin-induced hyperglycemia and insulitis in C57BL mice: influence of inbred background, sex, and thymus. Proc. Natl. Acad. Sci. U.S.A., 79, 630-634 (1982).

39) Verbeuren TJ, Jordaens FH, Zonnekeyn LL, Van Hove CE, Coene MC, Herman AG. Effect of hypercholesterolemia on vascular reactivity in the rabbit. I. Endothelium-dependent and endotheliumindependent contractions and relaxations in isolated arteries of control and hypercholesterolemic rabbits. Circ. Res., 58, 552-564 (1986).

40) Jonkers IJ, van de Ree MA, Smelt AH, de Man FH, Jansen H, Meinders AE, van der Laarse A, Blauw GJ. Insulin resistance but not hypertriglyceridemia per se is associated with endothelial dysfunction in chronic hypertriglyceridemia. Cardiovasc. Res., 53, 496-501 (2002).

41) Hirano K. Current topics in the regulatory mechanism underlying the $\mathrm{Ca}^{2+}$ sensitization of the contractile apparatus in vascular smooth muscle. J. Pharmacol. Sci., 104, 109-115 (2007).

42) Zicha J, Behuliak M, Pintérová M, Bencze M, Kuneš J, Vaněčková I. The interaction of calcium entry and calcium sensitization in the control of vascular tone and blood pressure of normotensive and hypertensive rats. Physiol. Res., 63 (Suppl. 1), S19-S27 (2014).

43) Florian JA, Watts SW. Integration of mitogen-activated protein kinase kinase activation in vascular 5-hydroxytryptamine2A receptor signal transduction. J. Pharmacol. Exp. Ther., 284, 346-355 (1998).

44) Ouchi Y, Han SZ, Kim S, Akishita M, Kozaki K, Toba K, Orimo $\mathrm{H}$. Augmented contractile function and abnormal $\mathrm{Ca}^{2+}$ handling in the aorta of Zucker obese rats with insulin resistance. Diabetes, 45 (Suppl. 3), S55-S58 (1996).

45) Ruiz-Torres A, Lozano R, Melon J, Carraro R. L-Calcium channel blockade induced by diltiazem inhibits proliferation, migration and F-actin membrane rearrangements in human vascular smooth muscle cells stimulated with insulin and IGF-1. Int. J. Clin. Pharmacol. Ther., 41, 386-391 (2003). 